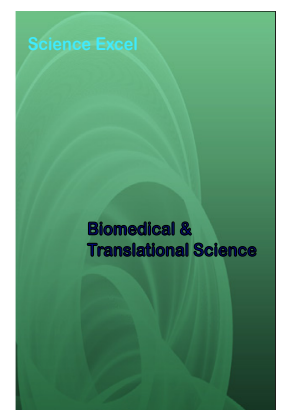

Correspondence

Alen J Salerian

Nestoros 40,Vravrona Greece E-mail: alensalerian@gmail.com

Phone: 698-742-8063

- Received Date: 31 Mar 2021

- Accepted Date: 05 Apr 2021

- Publication Date: 09 Apr 2021

Keywords: stem cells; gut microbes; Christensenellaceae; Malassezia; breastmilk bacteria.

\section{Some Infections May Be Endogenous}

\author{
Alen J Salerian \\ NESTOROS 40,Vravrona, Greece
}

Copyright

(C) 2021 Science Excel. This is an openaccess article distributed under the terms of the Creative Commons Attribution 4.0 International license.

\begin{abstract}
This paper advances a previous hypothesis "Human body may produces bacteria", and proposes that some infections may be endogenous.

It has been demonstrated that the Christensenellaceae, a family in the phylum Firmicutes, is heritable suggesting that human genetic material and gut bacterial material are related and human cells may generate some gut microbes It has also been shown that the fetus is exposed to bacteria prior to birth -without any evidence that they are contaminants or acquired from the environment -suggesting a possible endogenous origin of bacteria in breast milk, meconium, placenta, umbilical cord blood and amniotic fluid.

Malassezia yeasts are not contagious, not culturable from the environment, cannot colonize human skin by inoculation without occlusion and neonate skin is free of Malassezia but is colonized in the first month of life suggesting that they may be endogenous.

Human stem cells seem to be the most likely candidates to produce microbes: This is because they differentiate to epithelial cells and cancer cells and contain the essentials to transform to microorganisms. Future experimental studies are necessary to validate this hypothesis which may offer a new paradigm to combat opportunistic infections of possible endogenous origin.
\end{abstract}

\section{Introduction}

Since the introduction of the germ theory, it has been accepted that all infections result from foreign invading microbes [1]. However, a recent hypothesis proposed that human body may produce bacteria [2].

This paper hypothesizes that human stem cells may produce microbes and proposes that some infections are endogenous.

The evidence in support of this hypothesis," Some infections may be endogenous" is based upon diverse observations that will be discussed under four headings:

A. Multi potency of stem cells.

B. The origin of gut bacteria.

C. The origin of bacteria in breast tissue and milk.

D. The origin of Malassezia yeasts.

Multi Potency of Stem Cells

In multicellular organisms, stem cells are the earliest type of cell in a cell lineage and can differentiate into various types of cells and proliferate indefinitely to produce more of the same stem cell [3]. Epithelial tissues line the outer and inner surfaces of organs throughout the body and harbor stem cells that differentiate to epithelial cells [3].

It has been observed that, perhaps the most important and useful property of stem cells is that of self-renewal (4). Cancer cells may often originate from the transformation of normal stem cells and cancer cells may include 'cancer stem cells' - rare cells with indefinite potential for self-renewal that drive tumori-genesis (4). Stem cells contain a nucleus whereas bacteria have a nucleoid [5]. Using long-term lineage tracing, Lopez-Garcia et al., showed that the loss of a stem cell was compensated by the multiplication of a neighbor cell (5). The rate of stem-cell loss was equivalent to the rate of cell division, indicating that symmetric cell division was the rule for gut stem cells [6]. The Origin of Gut Bacteria

It has been shown that some gut bacteria (The Christensenellaceae, a family in the phylum Firmicutes) are heritable [7]. The Christensenellaceae's, relative abundance in the human gut is inversely related to host body mass index (BMI) in different populations making its relationship with BMI the most robust and reproducible link between the microbial ecology of the human gut and metabolic disease reported to date [7]. 
Heritable means genetic material is transmitted from a person to his or her offspring. In essence a human- a complex multicellular organism - passes on the genetic material of gut bacteria to his or her offspring. This also means the bacteria are not only part of the human but also produced by human cells and gut stem cells and gut microbes are genetically related. In addition, It has also been demonstrated that human genetics shape the composition of the gut microbiome in concert with environmental factors such as diet and lifestyle [7-14] . Furthermore, it has been demonstrated that variants in single genes (for example, LCT, NOD2 and FUT2) affect the composition of the gut microbiome [14].

It has also been demonstrated that host genetics dictate the composition of gut bacteria and 8 bacterial taxa were identified whose abundances were associated with single nucleotide polymorphisms in the host genome [14].

Nucleoid of bacteria forms a pseudo-compartment that frequently occupies a distinct region within the cellcharacterized by the absence of ribosomes - is functionally equivalent to the eukaryotic nucleus [5].

Taken together, the above findings suggest genetic information may be passed on from the nucleus of human cells to the nucleotide of bacteria.

\section{The Origin of Bacteria in the Fetus}

Until recently a medical dogma had prevailed that the fetus was sterile although today we know that the fetus is not sterile [15], amniotic fluid [16,17], meconium [18,19], breast milk $[20,21]$ breast tissue [22] umbilical cord blood [23], contain bacteria. Of importance the unique composition of bacteria of each subgroup is different [24] suggesting that they don't share a common origin. This observation contradicts the enteromammary translocation hypothesis [25] which proposes that bacteria from maternal gut may represent the common origin of bacteria in breast milk and tissue. In other words bacterial production is local.

\section{The Origin of Malassezia Yeasts}

Malassezia furfur was the first species described within the cosmopolitan yeast genus Malassezia, which now comprises 13 species [26]. Reported isolation rates of these species from healthy and diseased human skin show geographic variations [26]. There is evidence for an association with the host's genetics and with the M. Furfur strains similar to the genetic influences that shape gut microbes $[26,27]$.

Tinea versicolor a Malassezia yeast induced skin disorder is heritable [28-30], not contagious [28,29] and they have not been cultured from the environment [27] suggesting that they may also be endogenous. At birth neonate skin is Malassezia free [31] yet by the end of the first month is colonized by Malassezia [32]. It is very hard to explain this observation without considering the possibility of an endogenous origin partly because Malassezia infections are not contagious; it is difficult or impossible to colonize human skin by inoculation without occlusion [33] and finally Malassezia has not been cultured from the environment [27].

\section{Discussion}

Diverse and multiple observations support the hypothesis that some infections are endogenous however to date there has not been any experimental study to validate this novel

\section{Genetic Link Between Humans and Unicellular Organisms}

- $\quad$ Some gut microbes (the Christensenellaceae )are heritable and they are passed on from one generation to younger generations.

- Malassezia furfur yeasts are heritable and they are passed on from one generation to younger generations.

- Both gut microbes and Malassezia furfur yeasts are a part of normal human flora.

hypothesis. The strongest evidence to suggest a possible endogenous origin of microorganisms is the genetic link between humans and some human bacterial and fungal flora such as M. Furfur and The Christensenellaceae.

It can be argued that the human genetic influences- the heritability of some gut microbes and the observation that human genetics shape gut bacteria -are consistent with the endogenous origin of microbes yet, they may possibly represent influences associated with the host vulnerability to disease, infection or colonization.

It is also possible that the bacteria in breast milk and tissue are not contaminants but, they may originate from the mother. However, this possibility does not seem to be likely because the composition of bacteria in breast tissue and milk, Is different than the composition of bacteria from maternal gut, their proposed origin.

At birth neonate skin is Malassezia free yet by the end of the first month is colonized by Malassezia. It is very hard to explain this observation without considering the possibility of an endogenous origin partly because Malassezia infections are not contagious, it is difficult or impossible to colonize human skin by inoculation without occlusion and finally Malassezia has not been cultured from the environment.

It seems that stem cells differentiate to epithelial cells and cancer cells and are the most likely candidates to produce microorganisms. I t is necessary to experimentally demonstrate that human stem cells may produce microbes.

In summary "human stem cells may produce microbes" is a biologically sound hypothesis that is most likely accurate yet requires further experimental validation. Seems that this hypotheses may pave yet unexplored avenues to treat some opportunistic and burn wound infections.

\section{Declarations}

Funding

Alen J Salerian MD did not receive any funds.

\section{Conflict of interest}

Alen J Salerian MD has no conflict of interest.

Ethics approval

Not applicable.

Acknowledgments

None

Data sharing

Not applicable. 


\section{References}

1. Pasteur L. And the extension of the germ theory to the aetiology of certain common diseases. Comptes rendus del'Academie des Sciences.xc.Ernst,(Ttrans).1880;1033-44.H.C.

2. Salerian AJ. Human body may produce bacteria. Medical Hypotheses. 2017;103:131-132.

3. Van der Flier LG, Clevers H, Stem cells, Self Renewal, and Differentiation in the intestinal Epithelium. Annual Review of Physiology. 2009;71(1):24-260.

4. Reya T, Morrison S, Clarke M. et al. Stem cells, cancer, and cancer stem cells. Nature. 2001;414:105-111.

5. Thanbichler M, Wang SC, Shapiro L. The bacterial nucleoid: a highly organized and dynamic structure. J Cell Biochem. 2005 Oct 15;96(3):506-21.

6. Lopez-Garcia C, Klein AM, Simons BD, Winton DJ. Intestinal stem cell replacement follows a pattern of neutral drift. Science. 2010;330(6005):822-5.

7. Waters JL, Ley RE. The human gut bacteria Christensenellaceae are widespread, heritable, and associated with health. BMC Biol. 2019;17(1):1-11.

8. Hall $\mathrm{AB}$, Tolonen $\mathrm{AC}$, Xavier RJ. Human genetic variation and the gut microbiome in disease. Nat Rev Genet. 2017;18(11):690699.

9. Goodrich JK, Waters JL, Poole AC, et al. Human genetics shape the gut microbiome. Cell. 2014;159(4):789-799.

10. Goodrich JK, Davenport ER, Beaumont M, et al. Genetic Determinants of the Gut Microbiome in UK Twins. Cell Host Microbe. 2016;19(5):731-743.

11. Khachatryan ZA, Ktsoyan ZA, Manukyan GP, Kelly D, Ghazaryan KA, Aminov RI. Predominant role of host genetics in controlling the composition of gut microbiota. PLoS One. 2008;3(8):e3064.

12. Bonder MJ, Kurilshikov A, Tigchelaar EF, et al. The effect of host genetics on the gut microbiome. Nat Genet. 2016;48(11):14071412 .

13. Blekhman R, Goodrich JK, Huang $\mathrm{K}$, et al. Host genetic variation impacts microbiome composition across human body sites. Genome Biol. 2015;16(1):191.

14. Davenport ER, Cusanovich DA, Michelini K, Barreiro LB, Ober C, Gilad Y. Genome-Wide Association Studies of the Human Gut Microbiota. PLoS One. 2015;10(11):e0140301.

15. Stinson LF, Boyce MC, Payne MS, Keelan JA. The Not-so-Sterile Womb: Evidence That the Human Fetus Is Exposed to Bacteria Prior to Birth. Front Microbiol. 2019;10:1124.

16. DiGiulio DB. Diversity of microbes in amniotic fluid. Semin Fetal Neonatal Med. 2012;17(1):2-11.

17. D'Argenio V. The Prenatal Microbiome: A New Player for
Human Health. High Throughput. 2018;7(4):38.

18. Jiménez E, Marín ML, Martín R, et al. Is meconium from healthy newborns actually sterile?. Res Microbiol. 2008;159(3):187-193.

19. Ardissone AN, de la Cruz DM, Davis-Richardson AG, et al. Meconium microbiome analysis identifies bacteria correlated with premature birth [published correction appears in PLoS One. 2014;9(6):e101399].

20. Martín R, Langa S, Reviriego C, et al. Human milk is a source of lactic acid bacteria for the infant gut. J Pediatr. 2003;143(6):754758.

21. Cabrera-Rubio R, Collado MC, Laitinen K, Salminen S, Isolauri E, Mira A. The human milk microbiome changes over lactation and is shaped by maternal weight and mode of delivery. Am J Clin Nutr. 2012;96(3):544-551.

22. Urbaniak C, Cummins J, Brackstone M, et al. Microbiota of human breast tissue. Appl Environ Microbiol. 2014;80(10):30073014.

23. Jiménez E, Fernández L, Marín ML, et al. Isolation of commensal bacteria from umbilical cord blood of healthy neonates born by cesarean section. Curr Microbiol. 2005;51(4):270-274.

24. Costello EK, Lauber CL, Hamady M, Fierer N, Gordon JI, Knight R. Bacterial community variation in human body habitats across space and time. Science. 2009;326(5960):1694-1697.

25. Rodríguez JM. The origin of human milk bacteria: is there a bacterial entero-mammary pathway during late pregnancy and lactation?. Adv Nutr. 2014;5(6):779-784.

26. Gaitanis G, Velegraki A, Alexopoulos EC, et al. Malassezia furfur fingerprints as possible markers for human phylogeography. ISME J. 2009;3(4):498-502.

27. Velegraki A, Cafarchia C, Gaitanis G, Iatta R, Boekhout T. Malassezia infections in humans and animals: pathophysiology, detection, and treatment. PLoS Pathog. 2015;11(1):e1004523.

28. He SM, Du WD, Yang S, et al. The genetic epidemiology of tinea versicolor in China. Mycoses. 2008;51(1):55-62.

29. Hafez M, el-Shamy S. Genetic susceptibility in pityriasis versicolor. Dermatologica. 1985;171(2):86-88.

30. Salerian AJ. Twins With Endogenous Tinea Versicolor. International Journal of Case Reports. 2019;4:81.

31. Bell LM, Alpert G, Slight PH, Campos JM. Malassezia furfur skin colonization in infancy. Infect Control Hosp Epidemiol. 1988;9(4):151-153.

32. Powell DA, Hayes J, Durrell DE, Miller M, Marcon MJ. Malassezia furfur skin colonization of infants hospitalized in intensive care units. J Pediatr. 1987;111(2):217-220.

33. Faergemann J, Fredriksson T. Experimental infections in rabbits and humans with Pityrosporum orbiculare and P. ovale. J Invest Dermatol. 1981;77(3):314-318. 